\title{
Como a noite engendra o dia e o dia engendra a noite Revisando o vínculo da produção mútua entre escola e Modernidade
}

Pablo Pineau*

Resumo: O presente artigo analisa as relaçōes entre escola e Modernidade. A hipótese central é de que o triunfo da escola se baseia no fato de sua proposta ter sido capaz de pôr em ação a concepção educacional moderna, o que levou ao estabelecimento de uma relação de produção mútua entre ambas. Por meio de complexos e eficazes dispositivos, a escola moderna construiu subjetividades que comungavam a cosmovisão moderna. $\mathrm{O}$ artigo estabelece, a partir da produção histórica, um conjunto de dez premissas que se referem à concepção geral da escola, aos sujeitos intervenientes e às operaçóes levadas a cabo. Nesse percurso, recupera-se o debate educacional moderno.

Palavras chaves: educação; Modernidade; escola.

The way night engenders day and day engenders night Thinking over the connections of mutual production

between schools and modernity

Abstract: In this article, relations between schools and modernity are analyzed. The central hypothesis is that the success of schools is based on the fact that their proposals have made it

* Doutor em Educação pela Universidad de Buenos Aires. Professor da Universidad de Luján e da Universidad de Buenos Aires (UBA). Pesquisador e docente na Área de Educação e Sociedade da Facultad Latinoamericana de Ciencias Sociales (Flacso), Buenos Aires, Argentina. Algumas de suas publicações: Aseo y presentación. Un ensayo sobre la estética escolar. Buenos Aires: Latingráfica, 2008 (em coautoria com Di Pietro, Susana); El principio del Fin. Políticas y Memorias de la educación en la última dictadura militar (1976-1983). Buenos Aires: Colihue, 2006 (organizador da obra); Para una historia de la enseñanza de la lectura y la escritura en la Argentina. Del Catecismo Colonial a La Razón de mi Vida. Buenos Aires: Miño y Dávila, 2002. polpino@yahoo.com.ar.

I. O presente trabalho é uma revisão ampliada do texto "Premisas básicas de la escolarización como construcción moderna que construyó a la modernidad", publicado em 1999, na Revista de Estudios del Curriculum, (Versão espanhola do Journal of Curriculum Studies) volume 2, número I. Barcelona: Edições Pomares-Corredor.

Tradução: Rosiver Pavan (rosiver.pavan@gmail.com). Revisão técnica: Nora Rut Krawczyk 
possible to put modern education into action, fostering the establishment of a mutual production relation between schools and modernity. Thanks to complex and effective strategies, modern schools have built subjectivities sharing the same modern conceptions of the world. From the historical production, the author establishes a set of ten premises referring to the general concept of schools, the intervenient subjects and the operations that are concluded. The modern educational debate is recovered in this process.

Key words: educacion, modernity, schools.

Sem dúvida, o predomínio quase total da escola como forma educacional hegemônica em todo o globo foi uma das marcas distintivas da educação no século XX e constituiu-se uma das marcas de época. Por isso, já é lugarcomum na bibliografia pedagógica contemporânea sustentar a íntima vinculação que existe entre escolarização e Modernidade e, a partir disso, conceber a escola como "uma construção moderna construtora de Modernidade". Sem sombra de dúvida, a educação moderna - cuja forma por antonomásia é a escolarização - foi um dos motores principais do triunfo da Modernidade, assim como se converteu, por sua vez, em uma de suas maiores criações.

É possível rastrear na bibliografia um conjunto de hipóteses que se propóem a explicar este fato. A escola aparece, assim, como filha da república, filha do capitalismo, filha da cultura letrada, filha da nação ou filha da sociedade burguesa, dentre outras maternidades e paternidades possíveis. Em seu conjunto, todas elas ressaltam seu caráter moderno e modernizador, apresentam a íntima vinculação que existe entre escolarização e Modernidade, a partir do que se concebe a escola como "construção moderna construtora da Modernidade".

Junto disso, também é comum o enfoque de que, acompanhando a "dissolução no ar da solidez moderna" (Berman, 1980), produziu-se a "crise da escola”. A instituição escolar, que se apresentou durante décadas como uma maquinaria potente e eficaz, que foi centro de irradiação de saberes, aparato classificador de populações, dispositivo modernizador, edifício público privilegiado, ponto de encontro e recolhimento de crianças e jovens, território da cultura letrada, desfaz-se em migalhas e perde seu poder para passar a converter-se no último reduto em que ditos elementos resistem, debilitados, aos embates dos tempos atuais $^{2}$.

Em outros trabalhos ${ }^{3}$, argumentou-se a favor da necessidade de conceber a escola como uma forma educacional específica, artificial, macerada durante séculos em um espaço geográfico determinado - o ocidente europeu -, que se

2. Veja-se, a respeito, Caruso y Dussel (1996) y Colom y Mellich (1994).

3. Veja-se, entre outros, Alvarez Uría e Varela (1991), Hamilton, (1989) Pineau (1996), Ramírez e Ventresca (1992) e Trilla (1986). 
expandiu em muito pouco tempo (finais do século XIX, princípios do XX) por todo o globo e conseguiu tornar-se a forma educacional hegemônica em todo o mundo. Isso implicou um movimento especial de elementos que foram se amalgamando, muitas vezes de forma conflitiva e contraditória, para construí-la. Como se depreende, esse processo não foi harmônico e "natural", único ponto de chegada possível da "evolução" da humanidade e de seu devir educacional, mas produto de vários conflitos, contradições e oposiçôes.

Como se construiu essa aliança entre Modernidade e escola e como se deu o triunfo da escola e, dentro dela, o triunfo da organização curricular? Cremos que ambas as perguntas sejam as duas faces da mesma moeda e que a resposta a uma seja a mesma da outra. Proporemos como hipótese que a consolidação da escola como forma educacional hegemônica se deva ao fato de ela, a escola, ter sido capaz de encarregar-se da definição moderna de educação. Isto é, propomos que a Modernidade construiu uma forma específica de referir-se ao fato educacional e que a escola conseguiu apropriar-se dela e levar à ação dita concepção. A Modernidade ancorou-se na escola e a escola ocupou-se da modernização. Assim, na atualidade, a crise da Modernidade dá lugar a uma crise da escola, já que as bases - modernas - sobre as quais a instituição se construiu e se justificou perderam validade.

Buscaremos apresentar neste artigo as premissas sobre as quais a Modernidade, em um longo processo que durou séculos, construiu sua compreensão da educação. Para isso, privilegiamos dois momentos: de um lado, o escrito de Kant, Pedagogia ${ }^{4}$, produto dos apontamentos do curso homônimo que ministrou tal pensador para a formação do professorado de elite dos ginásios alemães na Universidade de Koninsberg. Nesse escrito, seu autor avançou na construção da educação moderna, retomando o pensamento pedagógico dos séculos XV a XVII e relacionando-o com a Ilustração, o que lhe permitiu começar a desdobrar as premissas educacionais modernas. De outro, o trabalho de Emile Durkheim, Educação e Sociologia ${ }^{5}$, de 1911, em especial o artigo "Educação", do Novo dicionário de Pedagogia e Instrução Primária, publicado naquele ano sob a direção de F. Buisson. Parece-nos importante destacar a definição de educação ali apresentada, já que consideramos que esta seja o ponto de maior expansão e desenvolvimento - ao menos do ponto de vista teórico - do empreendimento educacional moderno.

Durkheim definiu educação da seguinte maneira:

\footnotetext{
4. Tais apontamentos da aula de Kant foram tomados por seu discípulo Rink, sob a supervisão de Kant, e publicados pela primeira vez em 1803. Usaremos para este trabalho a edição de Akal Bolsillo, Madrid (1 983). Tradução de L. Luzuriaga e J.L. Pascual.

5. Estamos consultando aqui a edição da Editora Colofón, México (1 985).
} 
A educação é a ação exercida pelas gerações adultas sobre as que ainda não estão maduras para a vida social. Tem por objeto suscitar e desenvolver na criança certo número de estados físicos, intelectuais e morais que dela exigem a sociedade política em seu conjunto e o meio especial ao qual está particularmente destinada. (Durkheim, 1984, p.70).

Essa definição, ao longo do século XX, foi fortemente questionada e revisada, porém raramente superada. Relativizaram-se suas colocações - como a concepção de transmissão - somaram-se questôes — como as lógicas de poder ou a distribuição diferenciada de saberes —, porém a matriz de tal definição continua de pé. O poder de tal definição está, talvez, em que ainda não se construíram (ou pelo menos não conseguiram se tornar hegemônicas) novas conceitualizações de educação com semelhante nível de produtividade. Cremos que tal fortaleza se deva, exatamente, a que Durkheim foi capaz de conseguir a definição moderna de educação que condensou e potencializou como nenhuma outra as premissas que desenvolveremos de forma sucinta na continuação deste trabalho.

Premissa I: A Educação é um fenômeno que ocorre no sujeito autocentrado a partir do qual se irradia

Vale a pena começar este ponto recordando brevemente o percurso cartesiano: perante a dúvida, a aparência absoluta, a falsidade total, a mentira, o completo acidente, ergue-se, como uma rocha no devir imprevisível das águas, a certeza da existência do sujeito que pensa. Este sujeito unitário, autocentrado, racional, consciente de si mesmo, permitiu a concreção da Modernidade e, provavelmente, a instituição do sujeito cartesiano seja um dos pilares mais importantes sobre o qual se construiu a Modernidade.

A partir desta concepção, o sujeito preexiste a tudo mais. É a essência rodeada de aparência que estabelece limites claros, precisos e infranqueáveis entre ele e o mundo exterior. Compreende perfeitamente até onde chega seu ser - a essência racional, sua "consciência" - e onde começa tudo o mais, regido pelo acaso e a contingência, suscetível de ser modificado pelo "Demônio Maligno", que não poderá entrar nunca na fortaleza do sujeito.

Esse sujeito, além disso, regido pela razão, busca expandi-la o mais possível. Torna-se racional, calculador, planificador. Compreende e crê que, por meio da razão, sua função seja obter o controle do mundo exterior, ser capaz de frear e ordenar seu decorrer imprevisível e modificá-lo para a satisfação de seus fins. Vincula-se com o mundo a partir de uma postura exclusivamente ativa - é ele que conhece, estuda, investiga, compreende - enquanto o exterior ocupa ex- 
clusivamente o papel passivo de ser conhecido, estudado, investigado, compreendido. A clara fronteira determina também as ações a serem lavadas a cabo pelos termos do binômio - sujeito/mundo exterior - e a relação epistemológica que se estabelece entre eles.

Essa razão, que constitui sua essência, permite-lhe autocentrar-se e ser somente "idêntico a si mesmo", único e não replicável. Não apresenta pregas, zonas obscuras, fraturas, contradições e incoerências internas, mas é absolutamente consciente do que lhe ocorre e sucede. Daqui obtém sua soberania, enquanto ele é o próprio - e único - garantidor de sua independência. Guiado pela razão que lhe dá sentido, é consciente e responsável por suas decisóes, que são tomadas livremente.

É neste sujeito, com estas características - único, preexistente, soberano, completo, compacto, racional, planejador, ativo, autocentrado, limitado, idêntico a si mesmo, etc. - que se dará a educação moderna. A Modernidade precisa de um ponto de apoio a partir do qual possa se expandir e se disseminar e, diante do devir do mundo externo, o sujeito, fixo e quieto, é a opção. A educação não apenas ocorre nele, mas expande-se a partir dele, junto com a razão. Educação e razão, com sede no sujeito moderno, tecem, a partir de então, uma união indissolúvel. Convertem-se na ponte maciça que se estende entre um ponto seguro - o sujeito - até outro ponto seguro - as verdades - e que permite atravessar as águas tormentosas e imprevisíveis da realidade. Esse ordenamento vincula três elementos considerados essenciais: o sujeito - ponto de partida do ato de conhecer -, a razão/educação - a ponte - e as verdades - ponto de chegada. Esse caminho - do sujeito às verdades, de uma certeza a outra, de uma essência a outra essência -, por meio da razão, passa a ser para a Modernidade o ato educativo.

Premissa 2: A educação é um fenômeno humano que prescinde de qualquer alteridade

Junto com a constituição desse sujeito, especialmente por meio da determinação dos limites intransitáveis que o contêm e do estabelecimento da relação epistêmica mencionada, a Modernidade produziu uma essência humana que preenche o molde do sujeito com um material diferente do restante dos existentes: a condição de humanidade.

De um lado, produz-se uma distância dos elementos pré-modernos. Se até então o homem era apenas uma criação divina, a partir dali começa a somar outras dimensões, condensadas na racionalidade. Em tal processo, a educação será fundamental. Por exemplo, se, para as concepções medievais, a educação era uma via de comunicação com Deus e, portanto, a razão devia subordinar-se à fé, a Modernidade separou ambos os termos - os quais, por sua vez, começa- 
ram uma luta eterna para dominar-se mutuamente ${ }^{6}$ - e centrou o ato educativo na razão, a essência do sujeito moderno. A educação diferencia-se, assim, de outros fenômenos "espirituais", como a iluminação ou revelação, com os quais se amalgamava nos séculos anteriores e que ficaram no terreno da fé.

Por outro lado, já no ambiente da Modernidade, a humanidade diferenciase de outros registros mais "mundanos" como a animalidade, a natureza, o acaso, os excessos, os impulsos, os desejos, etc. Essas outras instâncias são entendidas como elementos negativos dos quais emerge o homem. Mais ainda, a possibilidade de maior distanciamento de tais substratos representa um avanço maior para a construção do sujeito moderno 7 . O homem provém da natureza, da animalidade, do acaso, da contingência, etc., porém, deve distanciar-se daí, deve desprender-se desses elementos para surgir puro e limpo e poder expandir e difundir sua razão. O empreendimento de tornar-se homem é o empreendimento de distanciar-se desses outros campos.

Porém, esses espaços não apenas são os lugares dos quais se tem que se separar, mas que também se convertem nos registros a serem dominados, detidos, controlados. O homem é homem quando maneja tais instâncias. A educação converte-se, então, em uma das formas privilegiadas de domínio desses registros e, por fim, de produção de sujeitos ${ }^{8}$. A educação é compreendida como um processo de irradiação de uma essência (apresentado na premissa anterior), originado de um centro - o sujeito - como possibilidade de controlar - e de se diferenciar de - o exterior. A confiança cega da ilustração nas capacidades humanas para "despejar" as trevas que prendem o homem e que lhe impedem o progresso se situam nessa premissa. Durkheim potencializou essa premissa com sua definição de educação, deslocando-a de qualquer definição não humana e limitando-a à esfera do social como conjunto ordenado de indivíduos.

Estabelece-se que o homem á capaz de conhecer, prescindindo de todo critério de autoridade e "alteridade", a partir do desenvolvimento de sua capacidade essencial que o inclina ao conhecimento: a razão. Esse fenômeno será compreendido como o processo educativo. De acordo com isso, Kant abre seu

\footnotetext{
6. Veja-se, a respeito, Vattimo e Derrida (1997).

7. É claramente identificável aqui a "lógica binária" que ordena o logocentrismo. Veja-se, a respeito, Derrida (197I).

8. Veja-se, a respeito, o sustentado por Locke: "Creio poder assegurar que, de cem pessoas, há noventa que são o que são, boas ou más, úteis e inúteis à sociedade, devido à educação que receberam. É daí que vem a grande diferença entre os homens" (Pensamientos sobre educación), e também por Kant, na obra já citada. Sustenta Kant: "Educar é desenvolver a perfeição inerente à natureza humana. [...] Unicamente pela educação o homem pode chegar a ser homem. Não é nada mais o que a educação o faz ser" (p.32).
} 
trabalho com a seguinte definição: "O homem é a única criatura que tem que ser educada. Entendo por educação os cuidados, a disciplina e a instrução. De acordo com isto, o homem é criança pequena, educando e estudante" (Kant, 1983, p. 29).

Dessa forma, a Modernidade converte a educação em processo pelo qual o homem se torna homem - sujeito moderno, cartesiano, com as características apresentadas no parágrafo anterior - e lhe dá sua essência por meio do desenvolvimento da razão, diferenciando-o, por sua vez, dos elementos pré-modernos - em especial, a vinculação com a divindade - e dos outros substratos aos quais deve dominar.

Premissa 3: A educação vincula-se fortemente com o progresso, com o futuro desejado, com o bem-estar geral. É via privilegiada de acesso à utopia

Anuladas - ou pelo menos limitadas - as potencialidades educacionais para alcançar uma vida melhor no pós-mundo, na "outra vida", na existência divina depois da morte corporal - como concebia o cristianismo medieval -, a Modernidade reorientou as finalidades educacionais para finalidades mais mundanas.

Expusemos já que sujeito e razão foram palavras-chave para a instituição da Modernidade. É necessário agora somar um terceiro termo: a idéia de progresso, de melhora no futuro. O século XVIII mudou as concepções temporais com as quais se movia o Ocidente até então - a decadência, a espera de rendição, o eterno retorno - e construiu a idéia de um devir temporal linear e acumulativo que permitiria à humanidade a construção de um futuro melhor. O evolucionismo do século XIX foi o ponto de maior desenvolvimento desta conceitualização.

A concepção moderna do tempo considera-o como um continuum que flui de forma regular e ordenada, como um rio de caudal constante. Daí se deduz a possibilidade de medi-lo, quantificá-lo e operar sobre ele. Solidária a essa concepção do tempo foram a individualização e a identidade pessoal do sujeito?.

Esse tempo moderno flui de um passado a um presente, e de um presente a um futuro. Este ponto último de chegada é o que orienta - ou deve orientar - o devir do fluxo. O futuro a chegar passa a ser uma construção do sujeito por meio da razão e, por isso, perfectível e melhorável. O sujeito, sob essa concepção do tempo, converte-se no artífice do futuro e de seu próprio destino. O que virá não será uma determinação sobre-humana - divina ou natural -, mas o produto do agir dos homens. Assim, quanto mais estes se movam pela razão,

9. Veja-se, a respeito, Elias (1989) e, para a questão mais especificamente educacional, Varela (1997). 
quanto mais dominem o exterior e suas partes "irracionais", melhor será o futuro a construir. Aí se situa a utopia.

As diferentes posições sociais modernas construíram a utopia de forma distinta: o mercado, para o liberalismo econômico; o comunismo, para o marxismo; a república, para o liberalismo político; o império da ciência, para o positivismo, etc., porém, todos sustentam o mesmo roteiro. A utopia, o futuro sonhado, imaginado, desejado, situa-se no final do caminho, e aí se chega por meio da razão. Passou-se do paraíso cristão para a utopia social, do céu à terra, do capricho divino à decisão humana, da degradação ao bem-estar. A utopia torna-se então uma essência, uma certeza, um ponto fixo e sólido no devir, converte-se na luz que guia o caminho dos sujeitos.

Como nos tópicos anteriores, é possível percorrer melhor esse caminho por meio da educaçãa. A partir dos aportes ilustrados, a educação, em sua união indissolúvel com a razão, permite a construção desse bem-estar geral, desse progresso, dessas utopias. Os fins educacionais deixam de estar na satisfação imediata das necessidades, ou na obtenção da outra vida, para situar-se no futuro melhor possível de ser construído pela humanidade racional.

Voltemos a analisar o que sustenta Kant a esse respeito:

É fascinante imaginar-se que a natureza humana se desenvolverá cada vez melhor pela educação, e que isto pode ser produzido de uma forma adequada para a humanidade. Descobre-se aqui a perspectiva de um futuro para a espécie humana [...] Um princípio da arte da educação [...] é que não se deve educar as crianças em conformidade com o presente, mas em conformidade com um estado melhor, possível no futuro, da espécie humana; ou seja, em conformidade com a idéia de humanidade e de seu destino completo (Kant, 1983, p.35 e segs.).

A educação passa a ser a pedra de toque do desenvolvimento do ser humano. Como no Aude Sapere, o desenvolvimento da razão é a via para alcançar o futuro perfeito. Isso implicou deixar de atuar sobre cada aluno para passar a fazê-lo sobre o conjunto deles. Dessa questão, ocupar-nos-emos no próximo tópico.

Premissa 4: A educação é uma prática de governamentalidade possível de ser regulada por meio da legislação

Em um texto clássico, Foucault (1981) adverte que um dos maiores obstáculos epistemológicos que a "ciência do governo" teve que superar foi deixar de atuar sobre o território e a família para começar a fazê-lo sobre a população. Isso foi conseguido no século XVIII e recebeu o nome de "governamentalidade".

A construção do poder moderno, do poder que atua por produção e não por repressão, que gera e não cerceia sujeitos, implicou a construção dessa estraté- 
gia, composta por saberes e por instituiçóes que tiveram como meta uma população e não mais o indivíduo ou a família. Do indivíduo ao conjunto, da parte ao todo, o poder conseguiu, no Ocidente, estabelecer os mecanismos e os dispositivos que lhe permitiram coagir o coletivo. A construção da educação como fenômeno moderno não escapou desse processo.

Kant estabelecia uma íntima vinculação entre educação e poder, resolvida por meio da problemática do governo que, em seu século, adotava a forma da governamentalidade. Afirmava em seu trabalho citado: "O homem pode considerar a arte do governo e a da educação como os dois descobrimentos mais difíceis." (Kant, 1983, p.35).

A educação, como forma de governamentalidade, foi afastada do âmbito individual ou familiar em que se inscrevia e convertida em um problema que afeta a todos os integrantes da comunidade. Os pensadores modernos - vale a citação de Kant como exemplo, embora Condorcet seja um exemplo obrigatório - são os que inauguram a reflexão da educação como fenômeno social que não atua sobre a alma de cada aluno, mas sobre a "consciência social" de todos.

Porém, essa passagem para a população como objeto de impacto não podia anular a atuação sobre cada um em particular. $O$ verdadeiro obstáculo epistemológico a superar foi conseguir atingir, ao mesmo tempo, o indivíduo e o conjunto, construir conjuntamente o governo e o autogoverno. O poder deve, em uma mesma operação, manifestar-se sobre todos para produzir em cada um, um sujeito determinado. O disciplinamento social implicava ao mesmo tempo o desenvolvimento de um disciplinamento individual - cujo ponto mais elaborado é a "autodisciplina" - que permitiria a interiorização das normas em cada um para seu exercício social e regulação coletiva.

Quando se alcança este fim - intervir ao mesmo tempo sobre cada um e sobre o coletivo, formar ao mesmo tempo o governo e o autogoverno - falamos de uma sociedade governamentalizada, da qual a educação moderna é uma das formas mais elaboradas. A organização pan-óptica do espaço, a conformação da "normalidade" como comando, com a qual se comparam todos, a geração de uma "ortopedia" pedagógica, o privilégio do exame, a coexistência do olhar psicológico e sociológico sobre o educacional são todos dispositivos que permitiram a construção da educação moderna dentro dos marcos da governamentalidade ${ }^{10}$.

Foucault sustenta, além disso, que a governamentalidade se encontra na base da construção do Estado moderno, como estado administrativo e racio-

10. A bibliografia a esse respeito é mais que abundante. Remetemos, para tal, especialmente a Foucault (1975). Para a aplicação dessa categoria na análise da educação, veja-se Popkewitz (1994; 1998) e Rousmaniere, Dahli e de Coninck-Smith (1997) para uma aproximação semelhante a partir da categoria "regulação moral". 
nal. A expressão "Tal assunto é razão de Estado" apresenta-se como o exemplo de dita operação. A inscrição do educacional no marco da população converteu a educação em um "problema de Estado". Esta alocação na arena do Estado torna a educação, sob os influxos liberais, um fenômeno possível - e digno - de ser legislável. A partir de então, toda construção com lógica de Estado - sejam as instâncias inferiores do nacional como aquelas superiores - considerou expedir regulamentos, leis, decretos, artigos, normas constitucionais, acordos internacionais, pactos, campanhas, etc. referentes ao educacional, como um tema prioritário de sua agenda. Direito e obrigação educacional, como termos indissolúveis, marcam em sua tensão as estratégias de governamentalidade em jogo.

Durkheim também contribuiu com essa premissa, construindo as seguintes equaçôes: Educação=Escola e Sociedade=Estado, de forma tal que de seu enunciado fundante "A educação é um processo social" transita-se para "a escola deve ser estatal".

\section{Premissa 5: A infância é considerada o sujeito educável por excelência}

Diversos trabalhos - dentre os quais se destaca o pioneiro de Ariès (1975) apresentaram uma diferenciação entre meninice e infância. Enquanto a primeira se inscreve no biológico e faz referência a um período imaturo da vida dos indivíduos, o conceito de infância inscreve-se no discurso social e busca dar conta de como a meninice se situa neste. A infância, então, é compreendida como uma construção social e, como tal, variável e situável historicamente.

Nos séculos anteriores, a inevitabilidade de ter filhos conduziu a uma escassa diferenciação dos espaços do mundo adulto e da infância. Compartilhavamse os quartos - geralmente únicos na casa -, os espaços de trabalho, da diversão, dos atos religiosos, das práticas educacionais. As escolas dos mercadores, ou as universidades, não estabeleciam requisitos cronológicos de ingresso, nem apresentavam diferenças no coletivo do alunado por critérios etários.

$\mathrm{Na}$ Modernidade iniciou-se o processo de diferenciação das idades e começou-se a interpelar a infância a partir de posturas fortemente negativas: sujeito incompleto, homem primitivo, "bom selvagem", perverso polimorfo, futuro delinqüente ou louco. Assim, colaborou-se para a construção da especificidade da infância, diferenciando-a do adulto, porém, sobretudo, atribuindo como característica definidora a de ser a etapa educativa por excelência do ser humano. Construiu-se um sujeito pedagógico, o aluno, e ele se tornou sinônimo de criança. Nesta linha, perguntava-se Kant: "Quanto deve durar a educação? Até a época em que a mesma Natureza decidiu que o homem se conduza por si mesmo, quando se desenvolve o instinto sexual, quando ele mesmo pode chegar a ser pai e deva educar." (Kant, 1983, p.42). 
Durkheim reforçou esta construção da infância como sujeito educável por excelência, compreendendo-a como sujeito social. Sustentava:

A sociedade encontra cada geração em presença de uma tábula quase rasa, na qual terá que construir com novo trabalho. Faz falta que, pelas vias mais rápidas, ao ser egoísta e associal que acaba de nascer, ela agregue outro capaz de levar uma vida moral e social. Eis aqui qual é a obra da educação e bem se vê toda sua importância (Durkheim, 1984, p.72).

Esta premissa permitiu imbricar fortemente pedagogia e infância ${ }^{11}$. Como toda população a ser disciplinada, a infância foi compreendida como um conjunto de indivíduos indóceis e inúteis (Foucault, 1975), porém, a essas características somou-se a de "incompletos" - cujo maior exemplo são as hipóteses da "tábula rasa". Educar foi, então, completar a criança para torná-la adulta. Assim, a pedagogia desenvolveu complexas e detalhadas classificações da infância, baseadas em justificativas biológicas, psicológicas e sociais ${ }^{12}$, e construiu a noção de "infância normal". Foi daí que as idéias de graduação e de adequação ao aluno se converteram nos pilares da pedagogia moderna.

Premissa 6: estabelece-se uma "moral de estado civil" para regular os vínculos entre os sujeitos participantes

"Não me perguntem quem sou, nem me peçam que permaneça invariável: é uma moral de estado civil a que rege nossa documentação. Que nos deixe em paz quando se trata de escrever". Com essa frase, Foucault encerrou a introdução em $A$ arqueologia do saber (1973). Retomemos daqui a idéia de "moral de estado civil" como categoria de ordenamento para analisar o vínculo pedagógico moderno.

As morais de "estado civil" constroem economias de processamento com base em categorias que respondem às seguintes características: estão préestabelecidas - não se podem criar novas -, são discretas - os limites entre elas são duríssimos -, são excludentes - não se pode ter mais de uma ao mesmo tempo -, são duradouras - supõe-se que se permaneça em tal categoria por tempos prolongados -, estão hierarquicamente ordenadas - não se pode percorrer os caminhos como se quer, pois eles são fixos - e, embora se possa passar de uma categoria a outra, tal passagem implica a realização de um ato que dá clara consciência aos sujeitos de que ele está produzindo uma mudança.

II. Veja-se, a respeito, Baker (1998).

12. Provavelmente, um dos pontos máximos alcançados por esta tendência seja a "piagetização" da pedagogia. Veja-se, a respeito, Walkerdine (1995). 
A relação pedagógica moderna foi construída sobre tais características. Docente e aluno, as únicas categorias possíveis, supõem as características apresentadas no parágrafo anterior como constitutivas da moral de estado civil ${ }^{13}$ que ordena a relação pedagógica. Isso implicou o estabelecimento de uma relação imutavelmente assimétrica professor-aluno, na qual o docente tem o que o aluno não tem e esses sujeitos se definem somente por sistemas de diferenças de carências entre eles ${ }^{14}$.

O aluno - construído sobre o infante - nunca é compreendido no processo pedagógico como um "igual" ou "futuro igual" ao docente - como o era, por exemplo, na velha corporação medieval -, mas indefectivelmente como alguém que sempre será menor em relação ao outro membro da díade. Isso permitiu a construção de uma série de mecanismos para seu controle, subordinação e degradação. O docente situa-se, na relação, como o modelo - físico, biológico, moral, epistêmico - a ser seguido pelo aluno para alcançar essa completude.

Historicamente, a construção da educação moderna acarretou o estabelecimento de outras morais que regularam a relação pedagógica. Talvez o exemplo mais conhecido seja o do Método Lancaster, muito difundido na primeira metade do século XIX, injuriado e destruído na segunda ${ }^{15}$. É possível sustentar que um dos motivos de sua derrota tenha sido a existência de um terceiro membro - o monitor - que não permitia o estabelecimento da moral triunfante. Um sujeito que pode ser ao mesmo tempo docente e aluno, que troca continuamente de categoria, começou a ser visto como um perigo para a educação moderna e causou sua desaparição.

A definição de Durkheim fixou as bases da relação em uma moral de estado civil. Estabelece-se nela muito fortemente o lugar do educador (as gerações adultas) e o do educando (as gerações que ainda não estão maduras para a vida social), com limites claros entre eles. Esses lugares são prioritariamente tomados pelos adultos e pelos infantes, respectivamente. A educação é um processo de "completude" da criança como sujeito inacabado ${ }^{16}$, sob a égide de uma "moral de estado civil". Educar-se é, simplesmente, ascender nas categorias.

13. Esta moral também estrutura a relação entre o docente e seus superiores.

14. Mais uma vez, a lógica binária denunciada por Derrida como estruturante do logos ocidental apresenta-se neste tema.

15. Veja-se, entre outros, Querrien (1982).

16. Reflexões semelhantes podem ser feitas sobre outros grupos "educáveis". Por exemplo, o "dever fardo do Homem branco" nas colônias, como o enunciava Kipling, era educar seres incompletos. Veja-se, além disso, para acrescentar outros casos, as considerações sobre as semelhanças nas colocações históricas das crianças em relação às mulheres, aos escravos, ao proletariado, aos negros e aos povos colonizados em Snyders ( 1 982). 
Premissa 7: A educação implica sempre uma instância de repressão e outra de liberação

A lógica binária que estrutura o logos torna a se apresentar na construção moderna da educação. Para a Modernidade, a educação implica um duplo processo de repressão e liberação conjunta e indiferenciável. Mudando os elementos, em todas as propostas pedagógicas modernas, algo - valorizado negativamente - deve ser reprimido para que outra coisa - valorizada positivamente - possa expandir-se ${ }^{17}$.

Voltemos uma vez mais a Kant. Este considerava que a educação se compunha de três partes: a criança, a instrução e a disciplina. A primeira é parte de todas as espécies animais, mas no homem sua necessidade se estende por mais tempo. Ao contrário, as outras duas instâncias são exclusivamente humanas. Assim diz o autor:

A disciplina é meramente negativa, enquanto ação que corrige a animalidade do homem; a instrução, ao contrário, é a parte positiva da educação. [...] (A disciplina) deve ocorrer cedo. Assim, por exemplo, se se enviam desde cedo as crianças à escola, não é com a intenção de que aprendam algo, mas com a de habituá-las a ficar tranqüilas e a observar pontualmente o que se lhes ordena para que, mais adiante, não se deixem dominar por seus caprichos momentâneos (Kant, 1983, p.30).

Esta relação entre disciplina e instrução - ambos os processos essencialmente humanos -, soldada por Kant, manteve-se nas bases da educação moderna. A inscrição do educacional como fenômeno essencialmente humano independente de toda alteridade fortalece a ligação deste par: o humano é o liberável e o não-humano é o reprimível. A relação instrução/disciplina, como complementação negativa/positiva, torna a reforçar as fronteiras precisas do educacional e o vínculo pedagógico baseado na moral de estado civil.

Durkheim reforça essa tendência por meio da inscrição social da educação na seguinte citação:

É a sociedade que nos puxa para fora de nós mesmos, que nos obriga a contar com outros interesses diferentes dos nossos; é ela que nos ensina a dominar nossas paixões, nossos instintos, a impor-lhes uma lei, a privar-nos, a sacrificar-nos, a subordinar nossos fins pessoais a fins mais altos. [...] É assim que adquirimos este poder de resistência contra nós mesmos, este domínio sobre nossas tendências, que é um dos traços distintivos da

17. Obviamente, este enunciado é uma referência ao trabalho de Lerena (1984). 
fisionomia humana e que se encontra tão mais desenvolvida quanto mais plenamente somos homens (Durkheim, 1984, p.77-78).

Dessa forma, educar implica, para a concepção moderna, uma dupla operação de repressão e liberação. Reprimir o corpo para liberar a mente - ou a alma - reprimir o animal para liberar o humano, reprimir os impulsos e os desejos para liberar a razão, reprimir a fala para liberar a concentração, reprimir o egoísmo para liberar a socialização, reprimir a infantilidade para liberar a idade adulta, reprimir a heterogeneidade para liberar a homogeneidade, reprimir a barbárie para liberar a civilização, reprimir o prazer para liberar o dever, reprimir o acaso para liberar a previsão, reprimir a dependência para liberar a liberação - perdoe-se a redundância -, etc. são diversas opções que apareceram ao longo do desenvolvimento da Modernidade, mas que continuam respondendo ao mesmo esquema de aproximação.

Premissa 8: Faz-se em alguma instituição de confinamento ou de reclusão, de acordo com a população atendida, baseado em uma aliança entre família e escola ou entre Estado e internado

Como apresentamos em premissas anteriores, o processo de constituição das "sociedades disciplinares" (Foucault, 1975), que a Modernidade acarretou, foi acompanhado da constituição da educação como fenômeno moderno. Podemos reescrever a pergunta foucaultiana sobre a prisão: "De onde vem essa estranha prática e esse curioso projeto de confinar para corrigir (que trouxe a época moderna)?" para referir-nos à escola: "De onde vem essa estranha prática e esse curioso projeto de confinar para educar (que trouxe a época moderna)?”.

A criação das sociedades disciplinares implica a articulação de três elementos: uma população - um coletivo de indivíduos que compartilham certas características - considerada inútil e indócil; uma instituição de confinamento ou de reclusão - de acordo com o grau de inutilidade e indocilidade de tal população - e uma disciplina - isto é, um conjunto de saberes - que regula a instituição e se aplica sobre a população para convertê-la em sujeitos úteis e dóceis. Para o caso educacional, a população foi por excelência a infância como apresentamos anteriormente -, a instituição foi a escola e a disciplina foi a pedagogia - como explicaremos mais adiante.

Como na prisão, um importante vício medieval pode ser encontrado no estabelecimento da escola como instituição de confinamento educacional: a matriz monástica. A escola retomou do mosteiro uma série de características e as reescreveu na lógica moderna. Em primeiro lugar, uma lógica espacial baseada na separação contundente entre um dentro e um fora. Assim, a lógica da 
instituição escolar repete a lógica de constituição do sujeito moderno - e sua função de irradiação - e a dupla liberação/repressão. A escola converte-se na caixa em que se conserva algo de positivo para os ataques do exterior negativo e, a partir dela, deve expandir-se para dominá-lo. A escola, templo da saúde, da civilização, da Pátria, da tradição, da razão, da ciência, do público, conserva e irradia esses bens sobre o exterior, reino da enfermidade, da barbárie, da antipátria, da novidade, da irracionalidade e do acaso, do saber não científico, da lei da selva.

Em segundo lugar, a escola é um "espaço educacional total" (Lerena, 1985). Nela, como no mosteiro, a totalidade dos fatos que se fazem são fatos educacionais. Nada do que ocorre nas aulas, nos pátios, nos recreios, na direção, no refeitório, no banheiro, escapa ao domínio da pedagogia. Finalmente, a pedagogia implica uma regulação "artificial" das açôes que ali se desenvolvem que responde às lógicas escolares e não às lógicas externas. Isto é, a regulação de uma escola localizada em qualquer parte do mundo tem mais em comum com outra localizada em qualquer outra parte muito distante do que com outras açôes que se realizam em espaços muito mais próximos fisicamente. Por exemplo, o calendário escolar é estipulado uniformemente para a totalidade do sistema, sem levar em conta o uso do tempo que faz a comunidade na qual a escola se situa ${ }^{18}$.

Como dizíamos mais acima, a opção pelo confinamento ou pela reclusão depende do grau de periculosidade da população. A infância "normal" foi confinada na escola e as infâncias "desgarradas" - órfãos, filhos sacrílegos, naturais, menores abandonados, menores delinqüentes, doentes mentais, etc. - foram reclusos em instituiçōes como os asilos, os orfanatos e os reformatórios ${ }^{19}$.

Tais práticas puderam ser conduzidas por meio de alianças. No caso do confinamento, uma aliança entre a família ${ }^{20}$ e a escola; no caso da reclusão, entre o Estado e o internato. Essas alianças puderam ser estabelecidas sobre o reconhecimento da validade e da legitimidade, por parte do "doador", da cultura da instituição e, por fim, por meio de uma submissão a ela para entregarlhe os infantes a seu encargo.

Já em citações anteriormente apresentadas, Kant expressava-se a respeito das vantagens de confinar precocemente as crianças nas escolas. Durkheim, já situado no terreno do público-estatal - como sinônimo do social - sustenta para fundamentar a aliança: "Faz falta que (a sociedade) assegure entre os cidadãos a suficiente comunidade de idéias e de sentimentos sem a qual a socieda-

18. Veja-se, a respeito, Escolano (1992).

19. Veja-se, a respeito, Franklin (1996) e Muel (1981).

20. Para a constituição da família como instituição moderna, veja-se o já clássico Donzelot ( 1987$)$. 
de é impossível; e para que isto possa produzir este resultado, é muito importante que não fique completamente abandonada ao arbítrio dos particulares (cf. os pais dos alunos)". (Durkheim, 1984, p.83).

Premissa 9: Há saberes básicos que todos os sujeitos têm que ter para pertencer à sociedade

Diversos processos que ocorreram entre os séculos XVI e XVII - entre os quais se destacam a invenção da Imprensa, a Reforma Religiosa e a constituição da teoria política liberal - supuseram que o sujeito moderno, constituído pela razão, devesse incorporar uma série de saberes medianamente complexos e elaborados para poder mover-se na sociedade. Foi se constituindo, então, um conjunto de saberes considerados indissolúveis, neutros e prévios a qualquer aprendizagem, cuja posse era ao mesmo tempo uma obrigação e um direito dos indivíduos e das sociedades.

Dentre estes, produziu-se uma construção que hoje nos soa natural: a lectoescritura. A nossos olhos, ler e escrever apresentam-se como as faces inseparáveis de um mesmo processo. Ao contrário, diversos trabalhos - dentre os quais destacamos Hebrard (1989) - demonstraram a historicidade de tal construção. Das tradições medievais do mercador de ler-contar e do monge de lerescrever (como cópia) foi necessário percorrer um longo caminho, repleto de marchas e contramarchas, até chegar à construção da figura moderna dos saberes elementares e, daí, a sua entronização na instituição escolar por meio dos três Rs (ler, escrever, contar) ${ }^{21}$, aos quais lhes adicionada a moral cidadã e/ou a religião, dependendo de cada caso.

A citação de Durkheim que encerra a apresentação da premissa anterior permite-nos avançar nesse tema. Nela, o autor expóe a necessidade da posse de um conjunto de saberes por parte dos integrantes da comunidade para poderem ser parte dela, e propõe o Estado - garantidor do bem-estar geral e encarnação máxima e racional do social - como agente legitimado para produzir tal distribuição. Tal autor, além disso, sustenta a idéia de que o que as sociedades adultas devem transmitir às jovens no processo educacional são aqueles saberes que permitem a perpetuação da sociedade, ou seja, os saberes básicos que todos devem possuir. Sustenta:

(A educação) tem como objeto suscitar na criança: primeiro, um número de estados físicos e mentais que a sociedade à que pertence considera como não devendo estar ausente em nenhum de seus membros: segundo, certos estados físicos e men-

21. Do inglês: reading, (w)riting and (a)ritmethics. 
tais que o grupo social particular considera igualmente como devendo ser encontrados em todos os que o constituem (Durkheim, 1984, p.69).

A distribuição desses "saberes básicos" foi monopolizada pela instituição escolar ${ }^{22}$. Estes (saberes básicos) ancoraram-se fortemente na escola, que conseguiu se apresentar perante a sociedade como a única agência capaz de conseguir sua apropriação massiva.

Os "saberes elementares" deram lugar à constituição dos "conteúdos mínimos" presentes nas leis fundadoras dos sistemas educacionais modernos e, posteriormente, foram a base do curriculum, como organizador desses saberes mínimos e necessários para o pertencimento na sociedade. Qualquer que seja a definição que deste adotemos, indefectivelmente se faz referência a esse conjunto de saberes - muitas vezes em sentido amplo: condutas, atitudes, etc. que a escola deve garantir a todos os alunos ${ }^{23}$. A Modernidade recorta, da totalidade de saberes construídos pela humanidade, aqueles que se consideram necessários que sejam transmitidos às novas gerações, definindo dessa forma o "curriculum explícito" da instituição escolar. Deixa de fora, então, outra enorme quantidade de saberes de diversos tipos que constituem o que se denominou o "curriculum ausente". A esses dois tipos resta-nos somar o chamado "curriculum oculto", composto por aqueles saberes, geralmente de tipo atitudinal, que a escola transmite e inculca sem explicitá-lo.

O estabelecimento desse "curriculum proposto" não está isento de conflito. Qualquer que seja sua forma de determinação, este é produto de diferentes negociações entre os grupos intervenientes. Não é o resultado de um processo abstrato, a-histórico e objetivo, mas originado de conflitos, de compromissos e alianças de movimentos e de grupos sociais, acadêmicos, políticos, institucionais, etc., identificáveis. O curriculum, como conjunto de saberes básicos, é um espaço de luta - em que se incorporam e amalgamam tendências contraditórias - que não se mantém como um dado, mas toma formas sociais particulares e incorpora certos interesses que são, por sua vez, o produto de oposições e negociações contínuas entre os diferentes grupos intervenientes.

22. Dessa forma, escolarização converteu-se em sinônimo de alfabetização. Veja-se Graff ( 1987) para uma crítica histórica de tal hipótese.

23. A construção contemporânea das Necessidades Básicas de Aprendizagem da conferência de Jomtien em 1980 reescreve tal situação nos tempos atuais, porém respeita a premissa que vimos desenvolvendo. 
Premissa 10: Existem saberes específicos que se ordenam disciplinarmente para dar forma ao campo pedagógico

Em premissas anteriores sustentamos, seguindo Foucault (1975), que o estabelecimento de uma sociedade disciplinar precisa da conjunção de três elementos: uma população, uma instituição e uma disciplina. Já nos referimos aos dois primeiros. Dedicar-nos-emos aqui ao último.

A organização disciplinar, típica da Modernidade, implica uma maneira especial de ordenar o uso e a economia dos saberes em jogo numa determinada relação produtiva de poder/saber para gerar sujeitos úteis e dóceis. No que diz respeito ao educacional, essa organização de saberes foi a "pedagogia" ${ }^{4}$. Porém, uma vez constituída como campo $^{25}$, os diferentes enunciados lutam em seu interior para dominá-lo e gozar de validade e veracidade. Devem, para isso, construir seus critérios de completude, coerência, não-contradição e impô-los ao restante. Aquelas propostas que conseguem esse objetivo convertem-se nas "pedagogias hegemônicas" 26 de cada período histórico. Esse processo de constituição realiza-se por meio de articulações específicas de elementos puramente "pedagógicos" com as traduções de determinados enunciados que diversos discursos põem à disposição da pedagogia ${ }^{27}$.

Estamos propondo resgatar o conflito, e por seu meio a historicidade, do campo pedagógico. Qualquer que seja sua forma de determinação, é produto de diversas negociações entre os grupos intervenientes. Não é o resultado de processos abstratos, a-históricos e objetivos, mas originado de conflitos, compromissos e alianças de movimentos e grupos socialmente identificáveis. $\mathrm{O}$ campo pedagógico é um espaço de luta onde se incorporam e amalgamam tendências contraditórias. Não se mantém como um dado, mas toma formas sociais particulares e incorpora certos interesses que são, por sua vez, o produto de lutas contínuas, tanto entre os grupos dominados e dominantes como no interior dos mesmos.

As lutas no interior do campo pedagógico pela autoridade e pelo reconhecimento não obedecem a motivações exclusivamente epistemológicas ou políticas, mas a uma complementaridade variável entre ambas. Seus resultados não somente têm manifestaçôes no plano das idéias, mas também no âmbito das

24. Estamos partindo de uma definição muito lassa e um tanto prática de pedagogia: "conjunto de saberes não necessariamente coerentes, nem fechados, nem completos, que se organizam disciplinarmente para referir-se ao educativo". Esperamos aprofundar essa aproximação da questão em futuros trabalhos.

25. Tomamos esse conceito de Bourdieu (1990).

26. Este termo é fortemente devedor da categoría "pedagogia triunfante" utilizado por Dussel ( 1993 ) e pretende ser uma reelaboração da mesma.

27. Vejam-se, a respeito, os diversos trabalhos de Basil Berstein (1989; 1994). 
posições institucionais. Por exemplo, os que ficam fora do campo também ficarão desautorizados a participar dos debates. Dessa forma, na discussão sobre o método único e correto, apresenta-se em código a disputa entre diferentes concepçõos sociais sobre a educação. Não se trata somente de diferenças acadêmicas, mas de disputas pela constituição de sujeitos pedagógicos e do estabelecimento de uma especial relação entre sociedade e escola ${ }^{28}$.

Por exemplo, o século XIX assistiu a um forte debate entre a pedagogia como disciplina "científica" e a pedagogia "prática" e "memorista", que concluiu com o triunfo da primeira graças às contribuiçõos do positivismo nos fins do século. A aparição de instituições específicas que enraizaram esses saberes como as Escolas Normais -, a consolidação dos diferentes "métodos pedagógicos", a anexação das varáveis "profissionais" às "vocacionais" nas definições de docente implicaram a constituição de um campo de produção e de circulação de saberes pedagógicos que definiu seus próprios limites e regras de jogo, no seio do qual se enfrentaram diferentes grupos e facçôes.

Por outro lado, o devir do campo pedagógico implicou duas reduções. Em primeiro lugar, entre os séculos XVIII e XIX, reduziu-se ao campo escolar. Em segundo lugar, no século XX, sobretudo na segunda metade, o escolar foi limitado ao curricular. A lógica da redução - e subordinação - transitou pela cadeia Pedagogia-escola-curriculum. Podemos colocar, então, que a imposição da organização curricular na escola foi uma importante disputa dentro do campo pedagógico e que pode ser associada ao triunfo de uma "racionalidade técnica" moderna, aplicada em sua forma mais elaborada na problemática educacional.

\section{À guisa de conclusão}

Buscamos neste trabalho apresentar a escola como tendo sido, ao mesmo tempo, uma das maiores criações da Modernidade e um dos motores principais de seu triunfo. Escola e Modernidade parecem ter estabelecido uma relação de produção mútua. Por meio de complexos e eficazes dispositivos, a escola moderna construiu subjetividades que comungavam a cosmovisão moderna. Aprendia-se a ser moderno principalmente, embora não exclusivamente, na escola. Ela ensinava a atuar sobre o mundo de acordo com certas premissas e matrizes que se articulavam com os efeitos de outras instituições modernas, tais como a família, o hospital, o quartel e a fábrica.

Produziu-se tal eficácia graças à escola ter sido capaz de pôr em ação as bases sobre as quais a Modernidade erigiu seu programa educacional. $\mathrm{O}$ triunfo da escola implicou processos modernizadores de unificação cultural (ética, estéti-

28. Veja-se, para o estudo de um caso - Finlândia -, Simola, Kivinen e Rinne (1997). 
ca, ideológica, etc.) nas populações sob seu encargo, que tiveram como efeitos o desenvolvimento do Estado moderno, a criação da nacionalidade como "imaginário compartilhado", a imposição de práticas e padrões simbólicos a todos os habitantes - como exemplo, a simbologia nacional —, a proibição e o controle de outras propostas e a criação de mercados de produção e consumo homogêneos e expansivos (Pineau, 2006).

Também cremos ser possível sustentar hoje que tais premissas perderam eficácia na atualidade, e isso provocou a crise da escola. Porém, isso não nos permite vaticinar, como já se fez muitas vezes, que "a escola morreu". Tal instituição, declarada falecida muitas vezes, demonstrou gozar de boa saúde e viu passar diante de sua porta o cadáver de seus inimigos. Nada faz supor que não volte a ressurgir uma vez mais.

A escola foi, sem dúvida, um dos atos de maior imaginação que a Modernidade enfrentou. No século XVI, sonhar com uma instituição em que todos os infantes freqüentassem para aprender certos saberes complexos, com sujeitos preparados para tal fim, desafiou todo o preestabelecido e ampliou enormemente as fronteiras da época. No século XIX, esse produto da imaginação ganhou corpo e, no XX, sobreveio aborrecimento e cotidianidade.

Talvez a maior herança que possamos obter de tudo isso seja a necessidade de tornar a realizar um ato imaginativo como foi esse. Nessa linha, o objeto deste escrito não é contribuir para a reconstrução da fragmentada educação moderna, mas ajudar a imaginar novas formas de compreender a educação e, assim, aproximar ferramentas de análise que dêem conta das problemáticas atuais, a partir de uma revisão dos formatos inquestionáveis - originais então, e esgotados agora - das premissas que apresentamos.

\section{Referências bibliográficas}

ALVAREZ URIA, Fernando; VARELA, Julia. Arqueología de la escuela. Madrid: La Piqueta, 1991.

ARIĖS, Philippe. La infancia y la vida familiar en el antiguo régimen. Madrid: Taurus, 1975.

BAKER, Bernadette. Child-centered teaching, redemption, and educational identities: a history of the present. Educational Theory, Spring, v. 48, n.2. Universtity of Illinois, 1998.

BERMAN, Marshall. Todo lo sólido se desvanece en el aire: la experiencia de la modernidad. Madrid: Siglo XXI, 1988.

BERNSTEIN, Basil. Clases, códigos y control I y II. Madrid: Akal, 1989.

. La estructura del discurso pedagógico. Madrid: Morata, 1994.

BOURDIEU, Pierre. Sociología y cultura. México: Grijalbo-Conacult, 1990. 
CARUSO, Marcelo; DUSSEL, Inés. De Sarmiento a los Simpsons: cinco conceptos para pensar la educación contemporánea. Buenos Aires: Kapelusz, 1996.

COLOM, Antoni; MELICH, Joan-Carles. Después de la modernidad: nuevas filosofías de la educación. Barcelona: Paidós-Papeles de Pedagogía, 1994.

DERRIDA, Jacques. De la gramatología. México: Siglo XXI, 1984.

DONZELOT, Jacques. La policía de la familia. Barcelona: Pretextos, 1987.

DURKHEIM, Emile. Educación y sociología. México: Colofón, 1984. Primeira edição: 1911.

DUSSEL, Inés. Existió una pedagogía positivista? sobre la formación de los discursos pedagógicos (1850-1900). Buenos Aires: UBA-FFyL, 1993. Mimeo.

Curriculum, humanismo y democracia en la enseñanza media (1863-1920). Buenos Aires: FLACSO-Centro de Publicaciones del CBC, 1997.

ELIAS, Norbert. Sobre el tiempo. México: FCE, 1989.

ESCOLANO, Agustín. Tiempo y educación. Notas para una genealogía del almanaque escolar. Revista de Educación, n. 298. Madrid: Ministerio de Educación y Ciencia, 1992.

FOUCAULT, Michel. Vigilar y castigar. Buenos Aires: Siglo XXI, 1975.

. La arqueología del saber. México: Siglo XXI, 1980.

. La gubernamentabilidad. AAVV Espacios de Poder. Madrid: La Piqueta, 1981.

FRANKLIN, Barry (Comp.). Interpretación de la discapacidad: teoría e historia de la educación especial. Madrid: Pomares-Corredor, 1996.

GRAFF, Harvey. The legacies of literacy. Indiana: Indiana University Press, 1987.

HAMILTON, David. Towards a theory of schooling. Londres: The Falmer Press, 1989.

HEBRARD, Jean. La escolarización de los saberes elementales en la época moderna. Revista de Educación, n. 288. Madrid: Ministerio de Educación y Ciencia, 1989.

KANT, Emanuel. Pedagogía. Madrid: Akal, 1983. Primeira edição: 1803.

KEMMIS, Carl. El curriculum: más allá de la teoría de la reproducción. Madrid: Morata, 1985.

MUEL, Francine. La escuela obligatoria y la invención de la infancia normal. Espacios de Poder. Madrid: La Piqueta, 1981.

PINEAU, Pablo. La escuela en el paisaje moderno: consideraciones sobre el proceso de escolarización. In: CUCUZZA, Rubén (Comp.). Historia de la educación en debate. Buenos Aires: Miño y Dávila, 1996.

- Algunas ideas sobre el triunfo pasado, la crisis actual y las posibilidades futuras de la forma escolar. In: BAQUERO, Ricardo; DIKER, Gabriela; FRIGERIO, Graciela. (Org.). Las formas de lo escolar. Buenos Aires: Del Estante editorial, 2006.

POPKEWITZ, Thomas. Las reformas de la formación docente en EEUU: Prácticas de regulación estatales, la Universidad y la Investigación. In: POPKEWITZ, Thomas (Comp.). Modelos de poder y regulación social en Pedagogía. Madrid: Pomares, 1994. 
. The production of reason and power: curriculum history and intelectual traditions. Journal of Curriculum Studies, v. 29, n. 2, p.131-164, 1998.

QUERRIEN, Anne. Trabajos elementales sobre la escuela primaria. Madrid: La Piqueta, 1980. ROUMANIERE, Kate, Dehli Kari y de Coninck-Smith, Ning (Ed.). Discipline, moral regulation and Schooling. A social History. Nueva York, Garland Publishing Inc, 1997.

SIMOLA, Hannu; KIVINEN, Osmo; RINNE, Risto. Didactic closure: professionalization and pedagogic knowledge in finnish teacher education. In: Teaching and Teacher Education. v. 13, n. 8, p. 877-891. Londres: Pergamon, 1997.

SNYDERS, George. No es fácil amar a los hijos. Barcelona: Gedisa, 1982.

TERIGI, Flavia. Notas para una genealogía del curriculum escolar. Propuesta Educativa, 14, Buenos Aires: FLACSO-Novedades Educativas, 1996.

TRILLA, Jaume. Ensayos sobre la escuela. Barcelona: Laertes, 1987.

VARELA, Julia. Categorías espacio-temporales y socialización escolar. Del individualismo al narcisismo. In: LARROSA, Jorge (Ed.). Escuela, poder y subjetivación. Madrid: La Piqueta, 1992.

VATTIMO, Gianni; DERRIDA, Jacques (Comp.). La religión. Buenos Aires: De La Flor, 1997.

WALKERDINE, Valerie. Psicología del desarrollo y pedagogía centrada en el niño. La inserción de Piaget en la educación temprana. In: LARROSA, Jorge (Ed.). Escuela, poder y subjetivación. Madrid: La Piqueta, 1995.

Recebido em 28 de março de 2008 e aprovado em 13 de junho de 2008. 